\title{
Synthesis of empty African horse sickness virus particles
}

\author{
Sonja Maree ,*, Francois F. Maree ${ }^{\mathrm{b}, \mathrm{h}}$, J ohn F. Putterill ${ }^{\mathrm{c}}$, Tjaart A.P. de Beer ${ }^{\mathrm{d}, \mathrm{e}, \mathrm{f}}$, Henk Huismans ${ }^{\mathrm{g}}$, J acques Theron ${ }^{\mathrm{h}}$
}

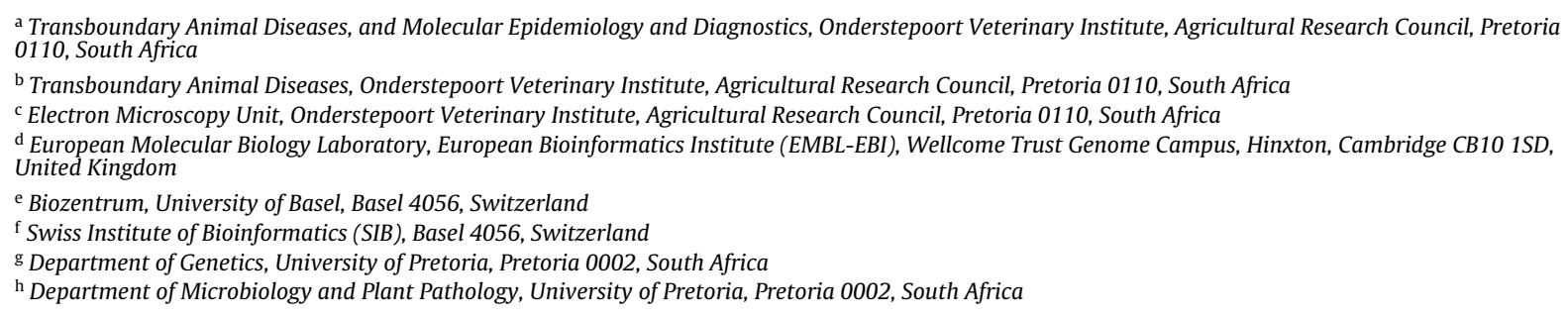

Keywords:

African horse sickness virus

AHSV

Core-like particles

Virus-like particles

VLP

\begin{abstract}
As a means to develop African horse sickness (AHS) vaccines that are safe and DIVA compliant, we investigated the synthesis of empty African horse sickness virus (AHSV) particles. The emphasis of this study was on the assembly of the major viral core (VP3 and VP7) and outer capsid proteins (VP2 and VP5) into architecturally complex, heteromultimeric nanosized particles. The production of fully assembled corelike particles (CLPs) was accomplished in vivo by baculovirus-mediated co-synthesis of VP3 and VP7. The two different outer capsid proteins were capable of associating independently of each other with preformed cores to yield partial virus-like particles (VLPs). Complete VLPs were synthesized, albeit with a low yield. Crystalline formation of AHSV VP7 trimers is thought to impede high-level CLP production. Consequently, we engineered and co-synthesized VP3 with a more hydrophilic mutant VP7, resulting in an increase in the turnover of CLPs.
\end{abstract}

\section{Introduction}

African horse sickness virus (AHSV), an arbovirus (genus Orbivirus) of the family Reoviridae, is the causative agent of African horse sickness (AHS), a highly infectious disease of equids of which the mortality rate in susceptible horse populations may exceed $95 \%$ (Coetzer and Guthrie, 2004). The AHSV genome is composed of 10 segments of linear double-stranded (ds) RNA, which encode four nonstructural proteins (NS1 to NS4) and seven structural proteins (Bremer, 1976; Grubman and Lewis, 1992; Zwart et al., 2015). The virion is a nonenveloped icosahedral particle (Oellermann et al., 1970; Burroughs et al., 1994) composed of three concentric protein layers (Manole et al., 2012). The core particle comprises of a VP7 surface layer and an underlying VP3 layer, which encloses the genomic dsRNA segments and three enzymatic minor proteins

* Corresponding author at: Agricultural Research Council, Onderstepoort Veterinary Institute, Transboundary Animal Diseases, Private Bag X5, Pretoria 0110, South Africa. Fax: +27 125299543 .

E-mail addresses: marees@arc.agric.za, mareef@arc.agric.za (S. Maree).
(VP1, VP3 and VP6). The core is surrounded by an outer capsid com-posed of VP2 and VP5, with VP2 being the major serotypespecific determinant and neutralizing antigen (Martı́nezTorrecuadrada et al., 1994, 1996; Roy et al., 1996; Scanlen et al., 1998).

African horse sickness is endemic in sub-Saharan Africa, but spo-radically escapes from its geographical area and extends to North Africa, the Middle East, the Arabian Peninsula and Mediterranean countries (Carpano, 1931; Alexander, 1948; Lubroth, 1988; Howell, 1963). Since no effective treatment exists for AHS, control of the disease relies on preventative vaccination programmes. To date, nine different serotypes of AHSV (AHSV-1 to AHSV-9) have been identified in Africa (Howell, 1962). In endemic areas, vaccination is performed by administration of combinations of representative live, attenuated strains of the different AHSV serotypes. Although serotypes 5 and 9 are excluded from vaccine formulations, these serotypes partially cross-reacts with serotype 8 and serotype 6, respectively (von Teichman et al., 2010). Despite their efficacy, AHS attenuated live virus vaccines are associated with several disadvantages. These include, amongst other, the risk of gene seg-ment reassortment between field and vaccine strains, the risk of 
introducing foreign topotypes into new geographical regions since vaccines are based on South African strains, and the lack of DIVA (differentiating infected from vaccinated animals) capability (Van Dijk, 1998; Mellor and Hamblin, 2004; Maclachlan and Guthrie, 2010).

The shortcomings of currently available AHS attenuated live virus vaccines have motivated efforts to develop alter-native safe and efficacious vaccines. Over the years, vaccines based on baculovirus-expressed AHSV capsid proteins (Martı́nezTorrecuadrada et al., 1994; Roy et al., 1996; Scanlen et al., 2002), DNA vaccines (Romito et al., 1999) and vaccines based on the use of poxvirus expression vectors (Chiam et al., 2009; Guthrie et al., 2009) have been pursued with varying degrees of success. A particularly promising approach for the development of an inherently safe AHS vaccine may be the production of virus-like particles (VLPs). These are self-assembling, non-replicating, non-pathogenic synthetic particles that mimic the native virus, as well as contain a diverse, repetitive high-density display of viral epitopes in the native conformation. VLP-based vaccines not only elicit humoral immune responses, but are also effective in stimulating $\mathrm{CD} 4^{+}$proliferative and cytotoxic T lymphocyte (CTL) responses (Grgacic and Anderson, 2006; Kang et al., 2009). These attributes render VLPs safer than the conventional vaccines and superior to recombi-nant single-protein subunit vaccines in eliciting strong, long-lived protective immune responses, even in the absence of adjuvants (Noad and Roy, 2003; Grgaciac and Anderson, 2006). Notably, VLPs of the prototype orbivirus, bluetongue virus (BTV), produced by baculovirus-mediated co-expression of the four major structural proteins (VP2, VP5, VP7 and VP3) in insect cells, were shown to stimulate a long-lasting protective immune response in vaccinated sheep (Roy et al., 1992, 1994; Stewart et al., 2010).

Previously, co-infection of insect cells with single-gene recombinant baculoviruses expressing the VP3 or VP7 proteins of AHSV was shown to permit the assembly of core-like particles (CLPs), albeit that this approach resulted in a low yield of mostly partially assembled CLPs (Maree et al., 1998). Consequently, the production of multilayered, heteromultimeric protein complexes, such as VLPs, has remained an elusive goal in the case of AHSV. Here, we report a recombinant baculovirus expression system that allowed the expression of various combinations of the four major AHSV-9 structural proteins and the assembly of CLPs, partial VLPs or complete VLPs. The efficient assembly of CLPs composed of VP3 and more soluble, but structurally similar mutant VP7 trimers, is also described.

\section{Materials and methods}

\subsection{Insect cells and viruses}

Spodoptera frugiperda clone 9 cells (Sf9; ATCC CRL-1711) were grown in suspension or in monolayer cultures at $27{ }^{\circ} \mathrm{C}$ in Grace's medium (Lonza) supplemented with $10 \%(\mathrm{v} / \mathrm{v})$ fetal bovine serum (FBS) and an antibiotics-antimycotic solution (streptomycin, penicillin and fungizone). Recombinant single-gene baculoviruses, 9.2, 9.3 and 9.7, which expresses the VP2, VP3 and VP7 proteins of AHSV-9, respectively, have been described previously (Maree et al., 1998; Venter et al., 2000).

\subsection{Construction of recombinant baculovirus transfer plasmid DNA}

Baculovirus pFastBAC-dual transfer plasmids (Invitrogen Life Technologies), containing different combinations of the coding regions of the four major structural proteins (VP2, VP5, VP3 and VP7) of AHSV-9, were constructed, as described below, according to standard procedures (Sambrook and Russell, 2001). The integrity and orientation of cloned inserts relative to the polyhedrin and $p 10$ promoters were verified by nucleotide sequencing.

To construct pFBd9.3-9.7, the VP7 coding sequence was isolated from plasmid pBR-9.7 (Maree et al., 1998) as a BglII fragment and cloned into the BamHI site of pFastBAC-dual to generate pFBd9.7. The VP3 coding sequence was recovered from plasmid pBR-9.3 (Maree et al., 1998) by digestion with BgllI and then cloned into the BbsI site of pFBd9.7 to complete construction of pFBd9.3-9.7. In this construct, the VP7 and VP3 coding sequences are under the transcriptional control of the polyhedrin and p10 promoters, respectively.

The wild-type VP7 coding sequence of pFBd9.3-9.7 was also replaced with a mutant version of VP7, which contains an insertion of six amino acids (KLSRVD) between position 177 and 178 . (Rutkowska et al., 2011). For this purpose, the wild-type VP7 coding sequence was excised from $\mathrm{pFBd} 9.3-9.7$ by digestion with Pst and partial digestion with $\mathrm{BamHI}$ ( $5^{\prime}$ internal site) and replaced with the mutant VP7 coding sequence, which was recovered as a BamHI/PstI DNA fragment from pFB9.7mt. The resulting plasmid was designated pFBd9.3-9.7mut.

For construction of pFBd9.6-9.7, the VP5 coding sequence was isolated as a BamHI fragment from plasmid pBS-9.6 (Du Plessis and Nel, 1997) and then cloned into the corresponding site of pFastBACdual to yield pFBd9.6. The VP7 coding sequence was recovered from pBR-9.7 as a SmaI/Sall fragment and cloned into the SmaI and Xhol sites of pFBd9.6. The derived construct, pFBd9.6-9.7, contains the VP5 and VP7 coding sequences under the transcriptional control of the polyhedrin and $p 10$ promoters, respectively.

To construct pFBd9.2-9.3, the VP3 coding sequence was recovered from plasmid pBR-9.3 by digestion with BglII, treated with Klenow polymerase and then blunt-end cloned into the Smal site of pFastBAC-dual to generate pFBd9.3. The VP2 coding sequence was isolated from plasmid pBS-9.2 (Venter et al., 2000) as a Sall/XbaI fragment and cloned into the corresponding sites of pFBd9.3. The resulting plasmid, pFBd9.2-9.3, contains the VP2 and VP3 coding sequences under the transcriptional control of the polyhedrin and p10 promoters, respectively.

\subsection{Generation of recombinant baculoviruses}

A recombinant baculovirus series, containing the expression cassettes as described above, was constructed by means of the BAC-to-BAC ${ }^{\mathrm{TM}}$ baculovirus expression system (Invitrogen Life Technologies), following the manufacturer's instructions. This series included 9.3-9.7 (VP3.VP7), 9.3-9.7mut (VP3.VP7mut), 9.6 (VP5), 9.6-9.7 (VP5.VP7) and 9.2-9.3 (VP2.VP3) baculoviruses. The progeny baculoviruses were plaque-purified and high-titre virus stocks were prepared according to the methods described by O’Reilly et al. (1994).

\subsection{Analysis of AHSV-9 capsid proteins expressed in insect cells}

Sf9 cells were infected with the recombinant baculoviruses at a multiplicity of infection (MOI) of $5 \mathrm{pfu} /$ cell. At $48-72 \mathrm{~h}$ post-infection, whole-cell lysates were analyzed by SDS-PAGE. Alternatively, radiolabelled proteins were prepared by starving infected cells of methionine for $1 \mathrm{~h}$ in methionine-free Eagle's medium (BioWhittaker) at $26 \mathrm{~h}$ post-infection, followed by addition of $15 \mu \mathrm{Ci}\left[{ }^{35} \mathrm{~S}\right]-$ methionine/ml and incubation for $3 \mathrm{~h}$. At $30 \mathrm{~h}$ post-infection, radiolabeled proteins in whole-cell lysates were separated by SDS-PAGE and detected by autoradiography. 


\subsection{Ultra-thin section electron microscopy of baculovirus-infected insect cells}

Monolayers of mock-infected Sf9 cells and cells infected with wild-type baculovirus (WT), 9.3-9.7 (VP3.VP7) or 9.3-9.7mut (VP3.VP7mut) at a MOI of $5 \mathrm{pfu} /$ cell were harvested at 48 h postinfection and suspended in $300 \mu \mathrm{l}$ of PBS to obtain a density of $1 \times$ $10^{7}$ cells $/ \mathrm{ml}$. An equivalent volume of pre-warmed $\left(37^{\circ} \mathrm{C}\right) 0.2 \mathrm{M}$ sodium cacodylate buffer ( $\mathrm{pH} 7.35$ ) containing $2 \%$ glutaraldehyde was added to the cell suspension, followed by addition of $200 \mu \mathrm{l}$ of pre-warmed $\left(40{ }^{\circ} \mathrm{C}\right) 2 \%$ agarose (Seakem Bacplaque). The cells were concentrated by centrifugation at $400 \times g$ for $2 \mathrm{~min}$ and fixed with the above buffered glutaraldehyde solution for $2 \mathrm{~h}$. The cells were post-fixed in $1 \%$ osmium tetroxide in $0.2 \mathrm{M}$ sodium cacodylate buffer ( $\mathrm{pH} 7.35$ ) for $2 \mathrm{~h}$, before being dehydrated in ethanol and embedded in resin (Araldyte 502). Ultra-thin sections were cut and collected on 300-mesh copper grids, stained in $2 \%(\mathrm{w} / \mathrm{v})$ uranyl acetate and Reynolds' lead citrate. The sections were viewed with a Jeol JEM-1200EX Mk-I transmission electron microscope at $80 \mathrm{kV}$.

\subsection{Purification and characterization of AHSV-9 particles}

Sf9 cells were infected with 9.3-9.7 (VP3.VP7) or 9.3-9.7mut (VP3.VP7mut) to synthesize CLPs. In order to synthesize partial VLPs, Sf9 cells were co-infected with 9.3-9.7 (VP3.VP7) and either 9.6 (VP5) or 9.2 (VP2). The synthesis of VLPs was investigated following co-infection with 9.6-9.7 (VP5.VP7) and 9.2-9.3 (VP2.VP3). Monolayers of Sf9 cells were infected with each of the appropri-ate recombinant baculoviruses at a MOI of $5 \mathrm{pfu} / \mathrm{cell}$ and infected cells were harvested by centrifugation at $48 \mathrm{~h}$. The cells were lysed on ice in $1 \mathrm{ml}$ of TNN buffer $(0.05 \mathrm{M}$ Tris- $\mathrm{HCl}$ [pH 8.0], $0.15 \mathrm{mM} \mathrm{NaCl}$, $0.5 \%$ [v/v] Nonidet P-40) per $2 \times 10^{7}$ cells. Following Dounce homogenization, the nuclei and cell debris were removed by low speed centrifugation $\left(400 \times g, 5 \mathrm{~min}, 4{ }^{\circ} \mathrm{C}\right)$. The clarified cytoplasmic extract was layered onto a discontinuous $10-40 \%$ (w/ v) sucrose gra-dient, prepared in $\mathrm{TN}$ buffer $(0.2 \mathrm{M}$ Tris- $\mathrm{HCl}[\mathrm{pH}$ 8.0], $0.15 \mathrm{M} \mathrm{NaCl}$ ), and centrifuged at $13500 \times \mathrm{g}$ for $90 \mathrm{~min}$ at $4{ }^{\circ} \mathrm{C}$. Twelve fractions of $1 \mathrm{ml}$ each were collected from the bottom of the gradient. Each frac-tion was diluted to a final volume of $4 \mathrm{ml}$ in TN buffer, centrifuged $\left(18000 \times g, 90 \mathrm{~min}, 4^{\circ} \mathrm{C}\right)$ and the pellets suspended in 50-200 $\mu$ l of TN buffer.

The concentrated samples were adsorbed onto Formvar carbon-coated, 400-mesh copper grids, washed by floating successively on droplets of TN buffer and then negatively stained with $2 \%(\mathrm{w} / \mathrm{v})$ uranyl acetate for $30 \mathrm{~s}$. The number of assembled AHSV particles in similarly prepared, semi-purified samples were counted over at least ten EM fields at a magnification of 60000 and the aver-age number of particles was determined. For detection of VP7 or VP5, EM grids preadsorbed with AHSV particles were floated on droplets of a 1:100 dilution of VP7 monoclonal antibody (Van Wyngaardt et al., 1992) or VP5 monospecific antiserum (Depart-ment of Genetics, University of Pretoria) for $20 \mathrm{~min}$. Grids were contrasted and examined with a Jeol JEM-1200EX Mk-I transmis-sion electron microscope at $80 \mathrm{kV}$.

\subsection{Structural modeling}

A homology model of a hexameric ring of AHSV-9 VP7 trimers in interaction with the underlying VP3 molecules was constructed with Modeller 9v1 (Fiser and Sali, 2003) by making use of the crystallographic reconstruction of an empty BTV-1 core from the VIPERdb database (Carrillo-Tripp et al., 2008) as structural template (pdb2BTV). Pairwise target-template sequence alignments were performed with ClustalX, i.e. VP3 of AHSV-9 and BTV-1 (GenBank and UniProt accession no. KJ156526 and P56582, respectively), and VP7 of AHSV-9 and BTV-1 (GenBank and UniProt accession no.
U90337 and P18259, respectively). A crystallographic reconstruction of the top domain of AHSV-4 VP7 (pdb1AHS) was also utilized as structural template to generate homology protein models of the top domain of the wild-type or mutant AHSV-9 VP7 proteins with the ESyPred3D homology modeling program (Lambert et al., 2002). All models were visualized and analyzed with the PyMOL Molecular Graphics System v0.98 (DeLano, 2002).

\section{Results}

\subsection{Synthesis and characterization of AHSV CLPS composed of VP3 and VP7}

To determine whether the major core proteins VP3 and VP7 of AHSV-9 can efficiently assemble into CLPs (Fig. 1 A), Sf9 cells were infected with 9.3-9.7 (VP3.VP7). Co-synthesis of unique proteins, of which the sizes agreed with those expected for the viral VP3 (90 $\mathrm{kDa}$ ) and VP7 (37 kDa), was confirmed by SDS-PAGE and autoradiography (Fig. 1B). The identity of the respective encoded proteins were confirmed with immunoblot analyses (Supplementary Fig. 1). Analysis of thin sectioned Sf9 cells by TEM revealed the formation of multimeric protein structures in vivo. At $48 \mathrm{~h}$ post-infection, the 9.3-9.7 (VP3.VP7)-infected cells exhibited ultrastructure largely consistent with that of wild-type baculovirus-infected cells. This included an enlarged nucleus containing abundant rod-shaped bac-ulovirus nucleocapsids. However, the most notable difference in 9.3-9.7 (VP3.VP7)-infected cells were the presence of two unique protein complexes. Cytoplasmic linear or paracrystalline arrays composed of empty nanoparticles of $c a .72 \mathrm{~nm}$ in diameter were identified (Fig. 1C). In addition to these complexes, large VP7 crys-talline structures were readily observed in the cytoplasm or nucleus of cells infected with 9.3-9.7 (VP3.VP7) (Fig. 1C). Autonomous crys-tal formation in vivo is a feature unique to AHSV VP7 amongst the orbiviruses (Burroughs et al., 1994; Maree and Paweska, 2005). No similar structures to those described above were observed in wild-type baculovirus-infected cells (Fig. 1D).

The self-assembled nanosized particles identified in insect cells co-synthesizing AHSV VP3 and VP7 were purified and examined by negative contrast TEM. The purified material exhibited a homogenous appearance with a diameter of $c a .72 \mathrm{~nm}$ (Fig. 1E), which is typical for authentic AHSV core particles (Fig. 1F), as described by Oellermann et al. (1970) and Burroughs et al. (1994). The icosahedral particles also displayed knob-like protrusions that radiated outwards, which is characteristic of the orbivirus ring-like arrange-ment of VP7 capsomers (Fig. 1E). The identity of the CLPs was verified by antibody decoration using VP7-specific monoclonal antibodies that bound to the surface of the particles (Fig. 1G and Supplementary Fig. 2). By comparison to undecorated CLPs, the surface-bound antibody in the presence of salts of the heavy metal uranium, resulted in a marked increase in the image contrast as strongly scattering matrix or cast that surrounded the weakly scat-tering proteins. The negative stain enveloped the particle surfaces and filled intervening spaces resulting in visibly coated particle images. The overall ultrastructure of the decorated particles were consistent with that of empty AHSV cores. The antibody did not bind to other heteromultimeric particles in the protein sample, such as baculoviruses.

\subsection{Synthesis and characterization of partial and complete purified AHSV VLPS}

The assembly of the AHSV capsid proteins into partial or complete VLPs was demonstrated utilizing co-infection approaches with two recombinant baculoviruses. The identity of the respective encoded proteins were confirmed with immunoblot analyses (Sup- 
A

9.3-9.7 (VP3.VP7)

CLP

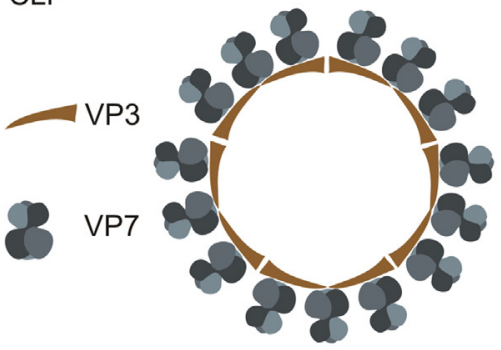

B

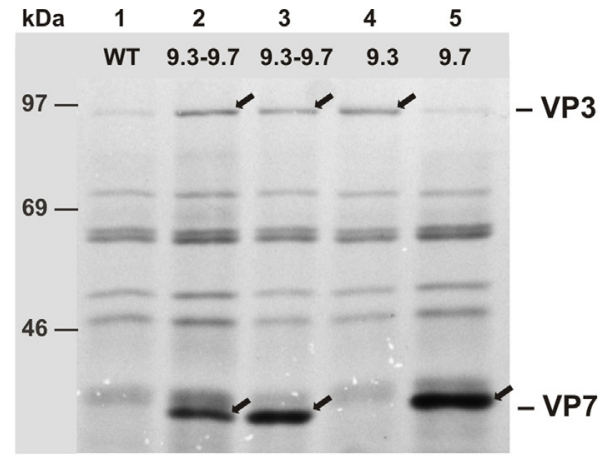

C

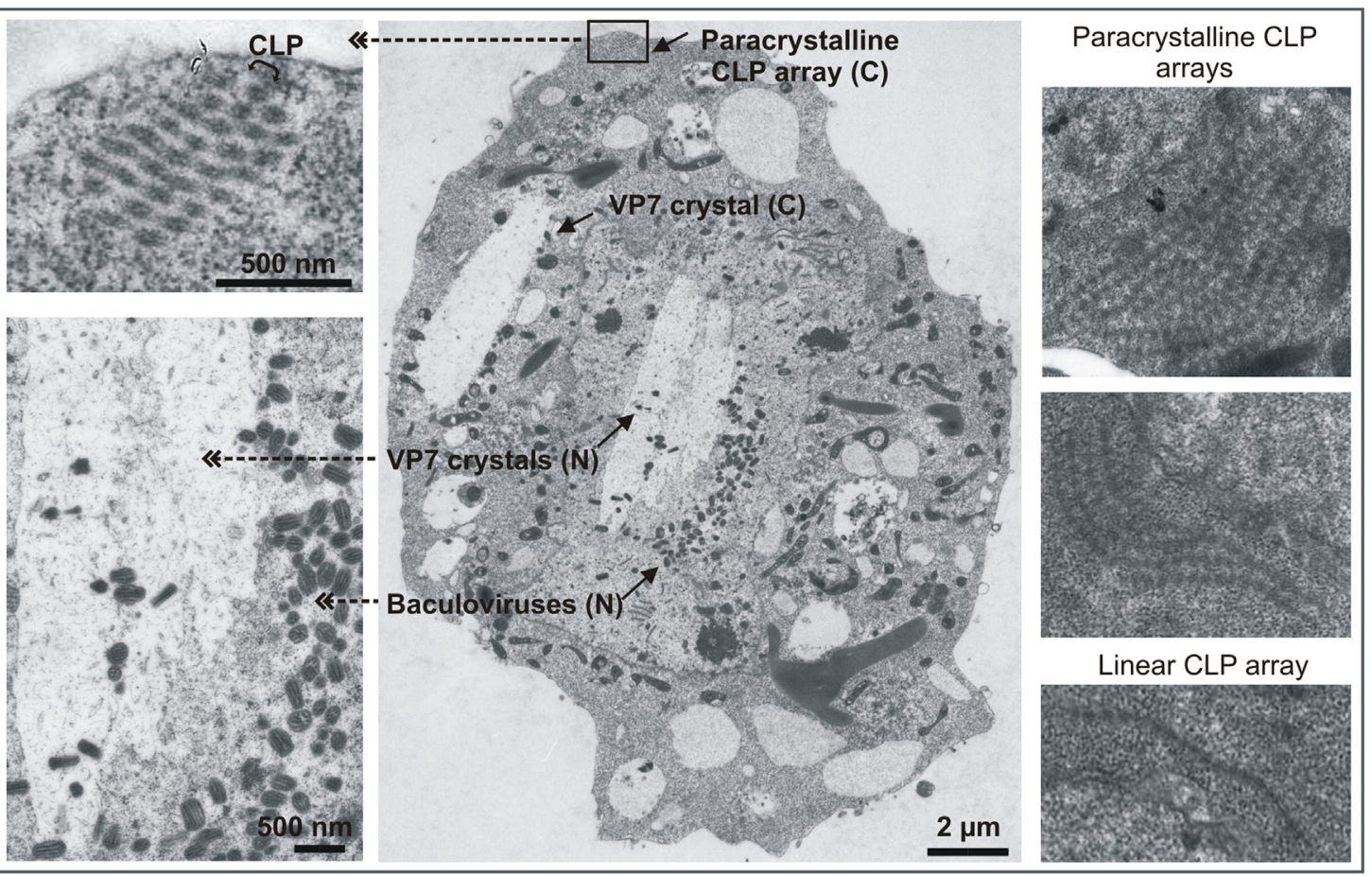

D

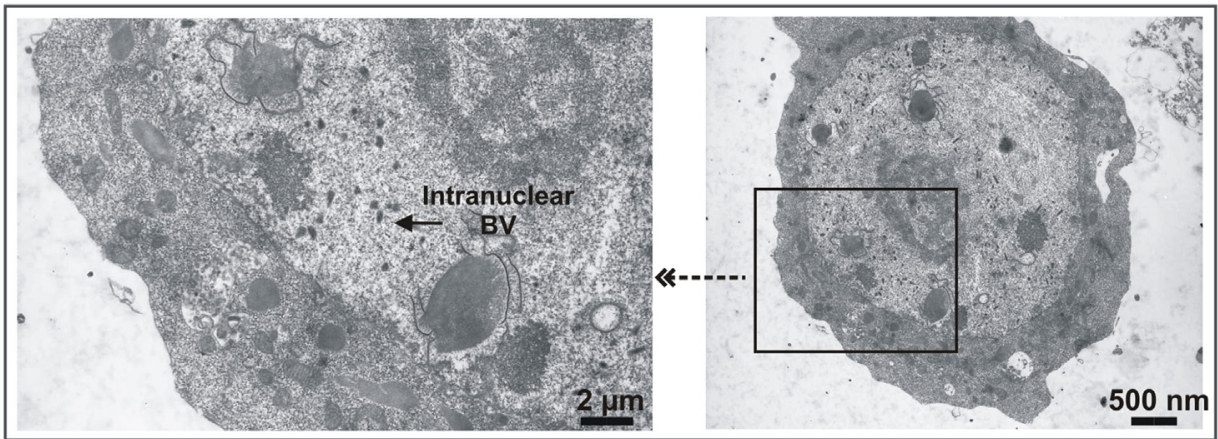

E

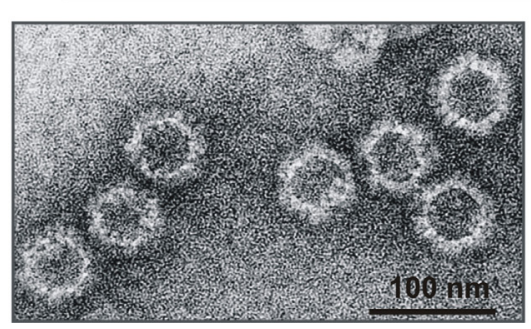

F

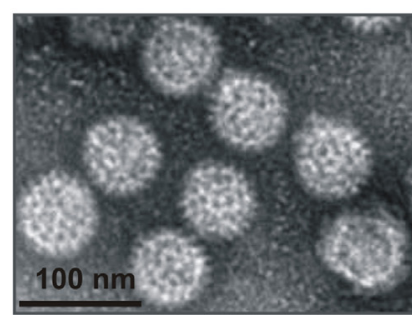

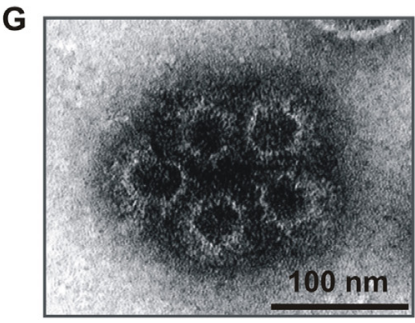

Fig. 1. Synthesis and characterization of AHSV core-like particles (CLPs).

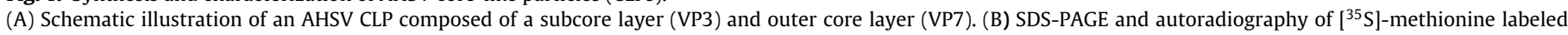

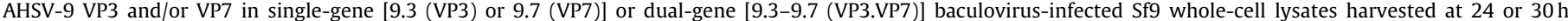

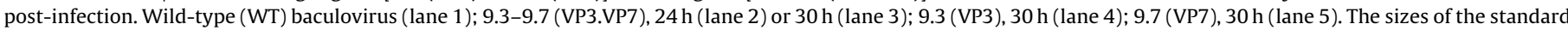

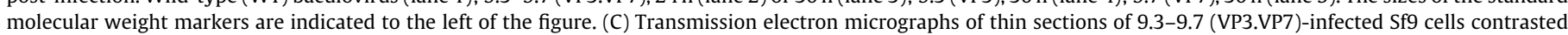

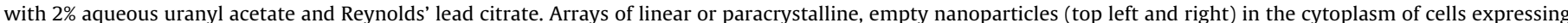

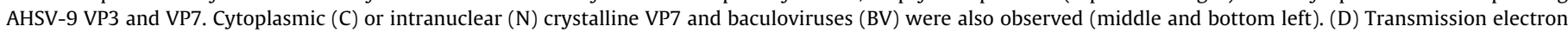


A

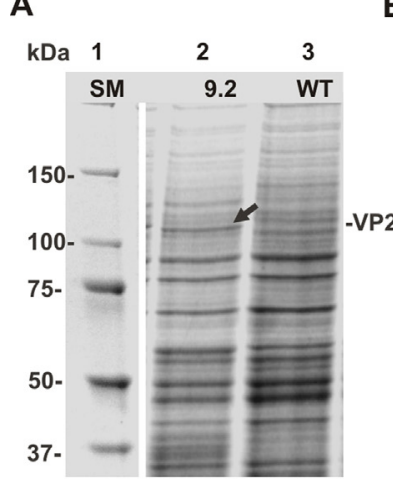

E
B

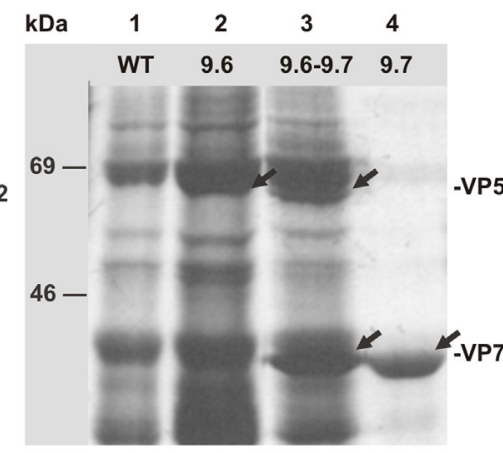

C

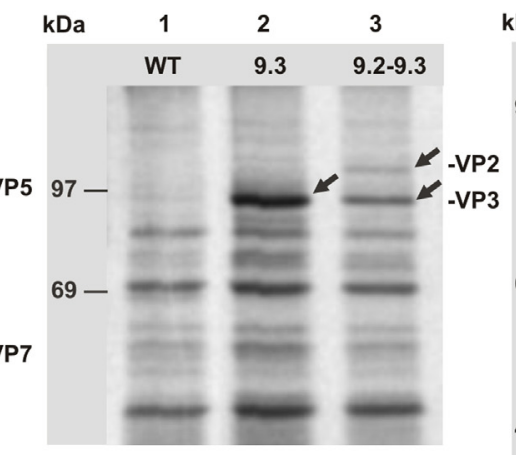

D

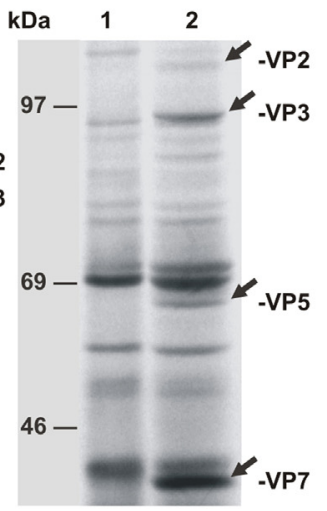

9.3-9.7 (VP3.VP7); 9.2 (VP2)

VP2 bound to CLP

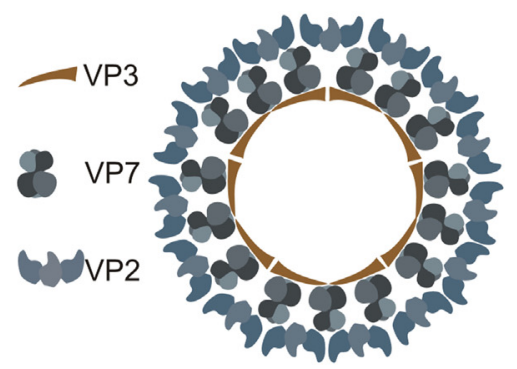

$\mathbf{F}$

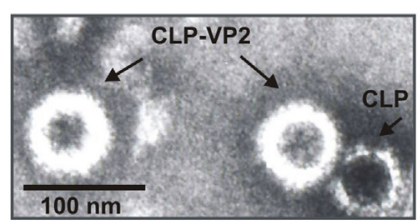

G
9.3-9.7 (VP3.VP7); 9.6 (VP5)

VP5 bound to CLP
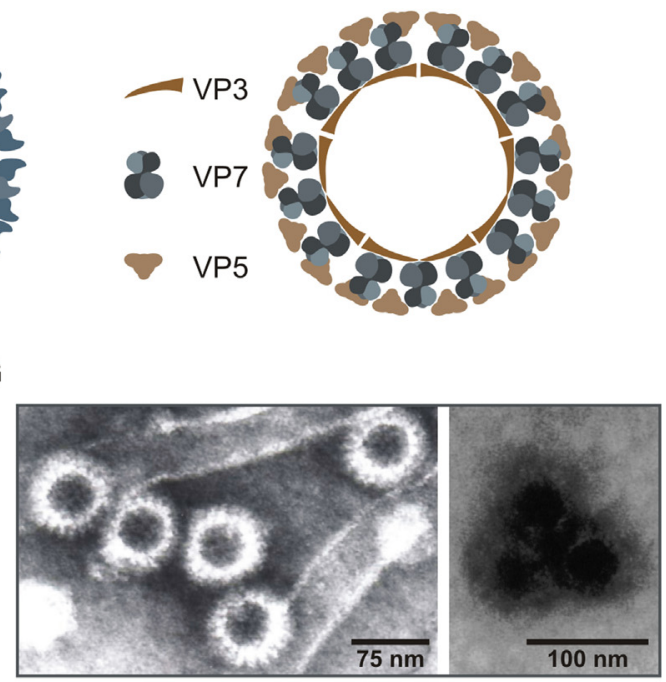

9.6-9.7 (VP5.VP7); 9.2-9.3 (VP2.VP3)

VLP

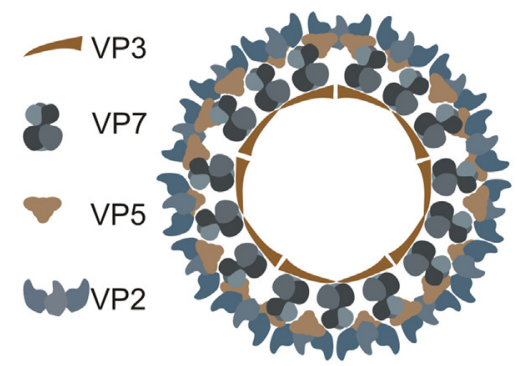

H

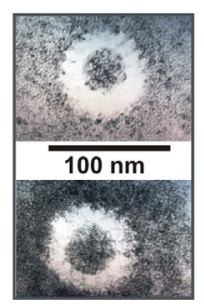

I

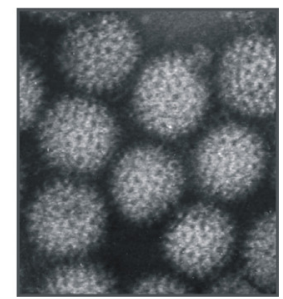

Fig. 2. Synthesis and characterization of AHSV partial and complete virus-like particles (VLPs).

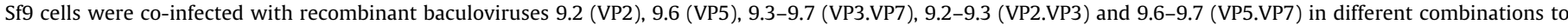

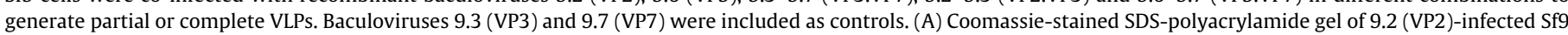

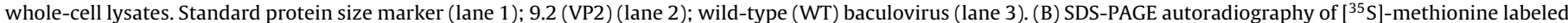

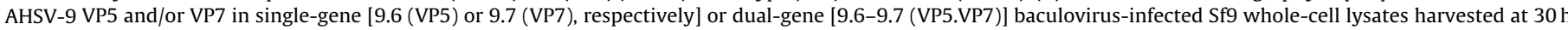

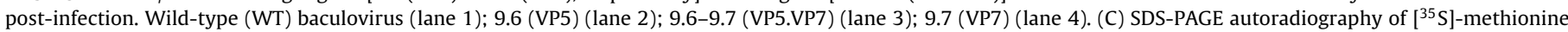

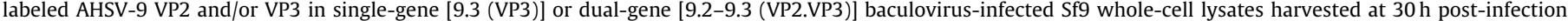

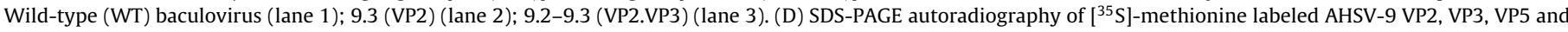

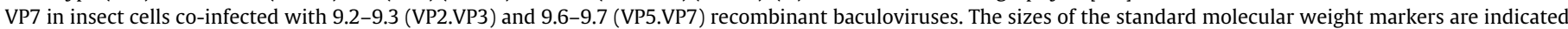

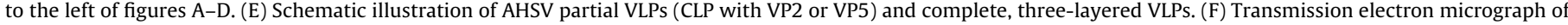

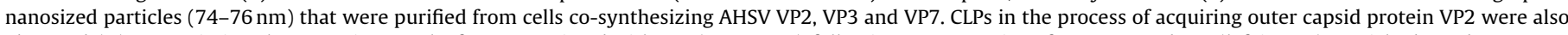

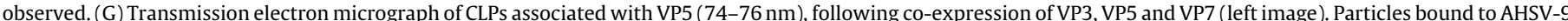

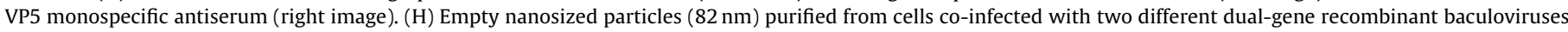
to express the four major capsid proteins (VP3, VP2, VP5 and VP7) of AHSV-9. (I) Authentic AHSV virions.

plementary Fig. 1). Infection of insect cells with 9.2 (VP2), 9.6-9.7 (VP5.VP7) or 9.2-9.3 (VP2.VP3) resulted in the expression of unique proteins of which the sizes agreed with those expected for the viral VP2 (109 kDa), VP5 (64 kDa) and VP7 (37 kDa), or VP2 and VP3 (90 kDa), respectively (Fig. 2A-C). Recombinant baculovirus, 9.3-9.7 (VP3.VP7), was also utilized to co-synthesize VP3 and VP7 (Fig. 1B).
To investigate whether the corresponding proteins of AHSV can independently interact with preformed AHSV CLPs to yield partial VLPs (Fig. 2E), both VP3 and VP7 were co-expressed in Sf9 cells with either VP2 or VP5. Subsequently, TEM analysis of negativelycontrasted particles, purified from Sf9 cells co-infected with 9.39.7 (VP3.VP7) and either 9.6 (VP5) or 9.2 (VP2), indicated that these structures were icosahedral, empty and had a maximum diameter of $76 \mathrm{~nm}$ (Fig. 2F and G). The capsids of putative CLPs associated

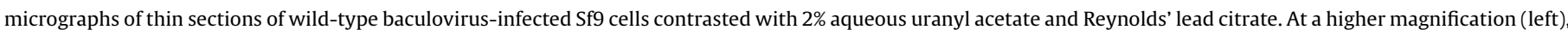

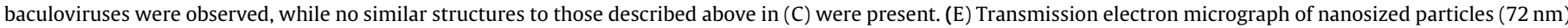

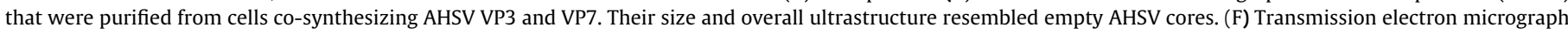
of authentic AHSV cores purified from virions. (G) TEM of CLPs bound to VP7-specific monoclonal antibodies. 
A
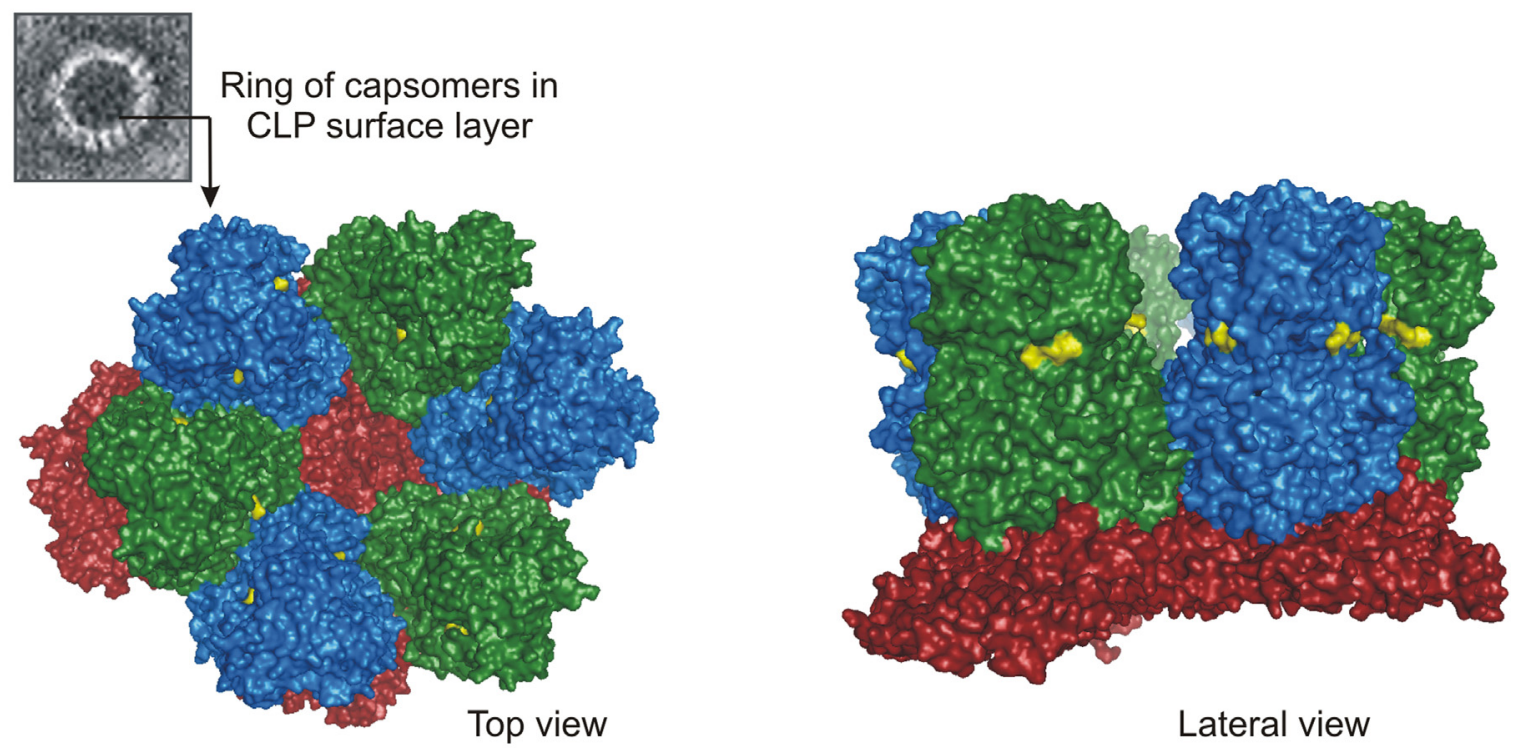

Lateral view

B

\begin{tabular}{lllllll|llllllllllllllllll|lllllll} 
Position & 20 & 21 & 22 & 23 & 24 & 25 & 26 & 27 & 28 & 29 & 30 & 31 & 32 & 33 & 34 & 35 & 36 & 37 & 38 & 39 & 40 & 41 & 42 & 43 & 44 & 45 & 46 & 47 & 48 & 49 & 50
\end{tabular}

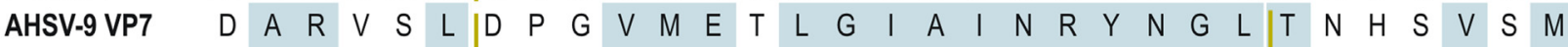

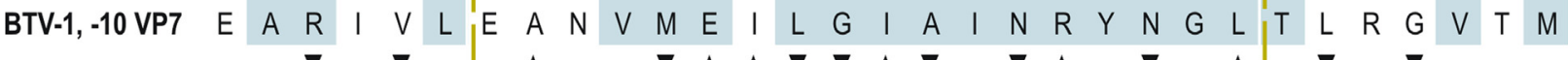

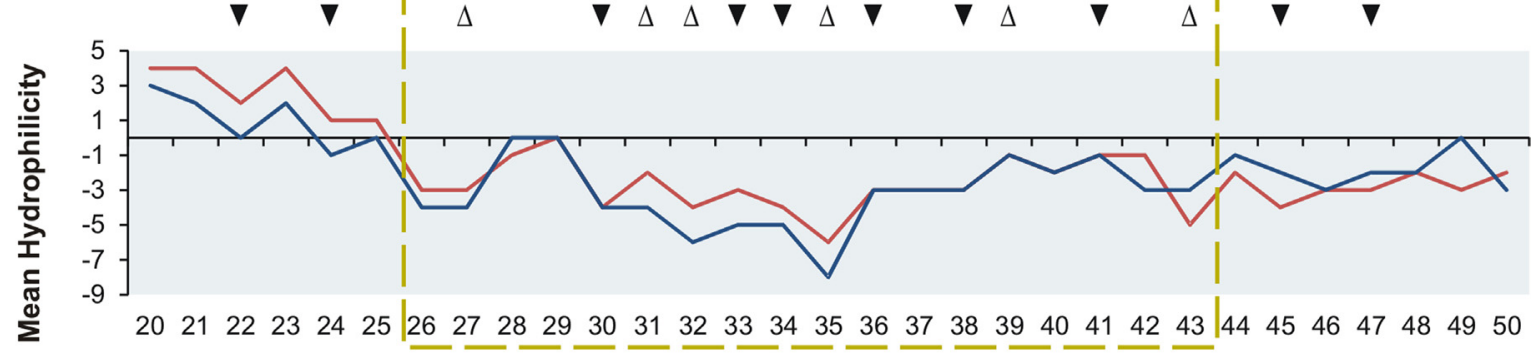

\section{Amino Acid Position -AHSV-9 VP7 - BTV-1 or -10 VP7}

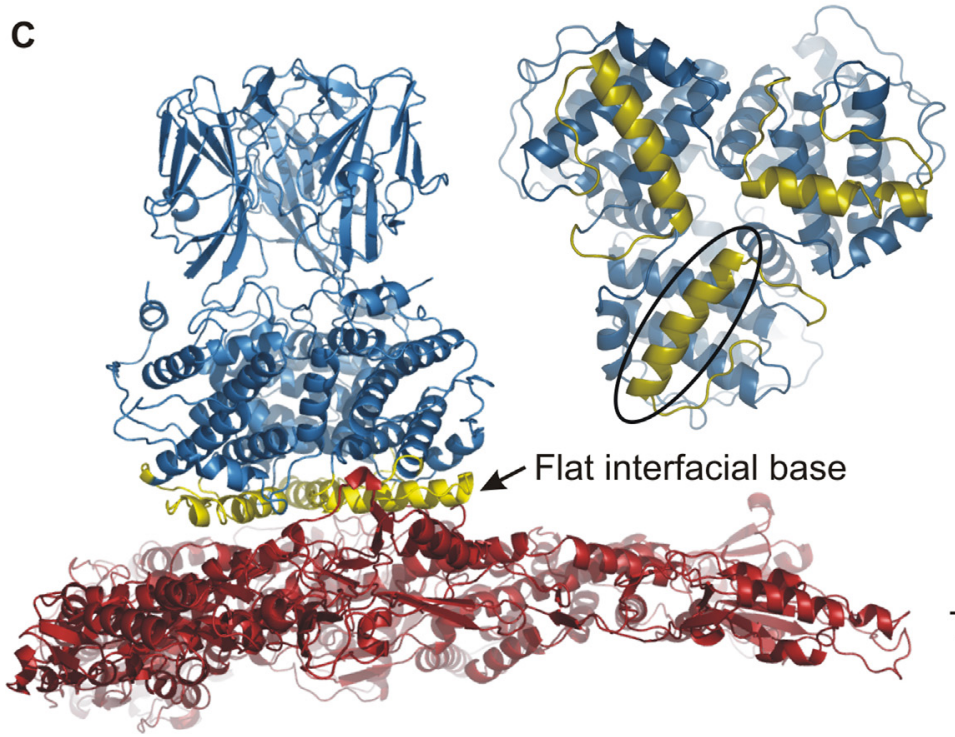

D

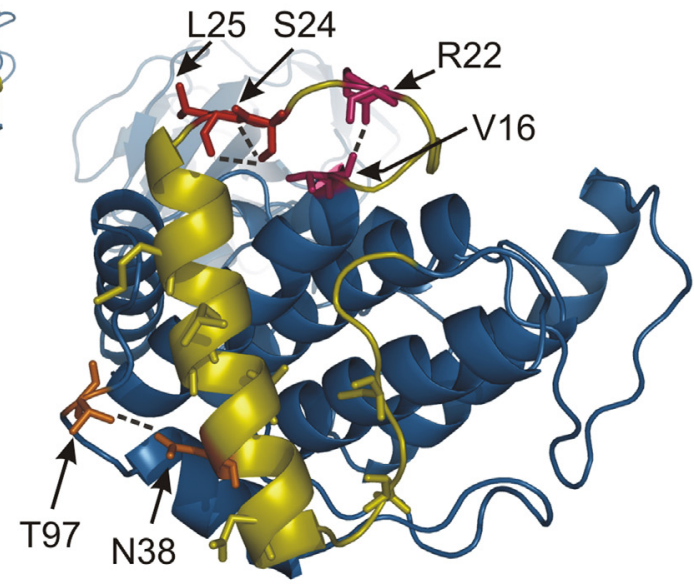

Fig. 3. Assessment of surface-exposed hydrophobic or flexible regions in VP7 trimers.

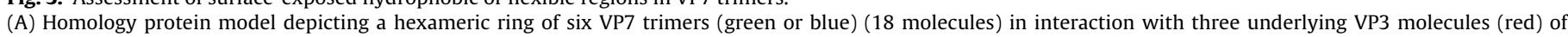

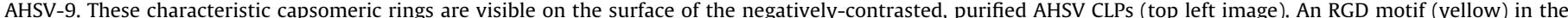

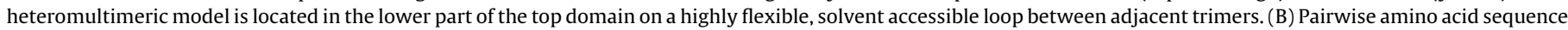

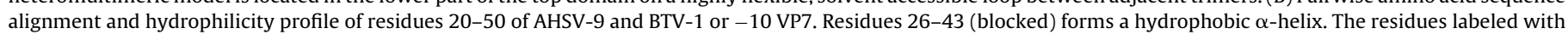


with VP2 were noticeably different from CLPs. Unlike the CLPs that were characterized by a prominent spiky, knob-like surface layer, the surface of particles associated with VP2 appeared smoother with a higher electron density. However, similar to CLPs, the empty particles produced in insect cells co-expressing VP3, VP5 and VP7 were characterized by a knobby surface ultrastructure, although a higher electron density was evident (Fig. 2G). In order to verify whether VP5 is indeed associated with AHSV CLPs, antibody deco-ration using a VP5 monospecific antiserum (Fig. 2G) was performed. The antiserum bound to these particles, but not to contaminating baculoviruses or cellular material. These results suggest that in the presence of AHSV CLPs, molecular interaction of VP2 or VP5 with the core surface layer does not rely on the presence of both proteins.

We next examined whether heterologous expression of the four major AHSV-9 capsid proteins could result in their selfassembly into VLPs (Fig. 2E). To accomplish this, Sf9 cells were coinfected with 9.2-9.3 (VP2.VP3) and 9.6-9.7 (VP5.VP7). By utilizing these specific recombinant baculoviruses, CLP production (comprised of VP3 and VP7) is only possible in co-infected cells and their for-mation is thus expected to coincide with the expression of both the outer capsid proteins VP2 and VP5. Coexpression of the VP5 and VP7 or VP2 and VP3 proteins were confirmed in cells infected with the appropriate baculoviruses (Fig. $2 \mathrm{~B}$ and $\mathrm{C}$, respectively), while co-expression of all four capsid proteins were confirmed in cells infected with both of these baculovirus vectors (Fig. 2D). Multimeric particles were purified at $48 \mathrm{~h}$ post-infection and their morphology was subsequently analyzed by TEM. Assembly inter-mediates representing forms of CLPs in the process of acquiring the outer coat components were observed. In addition, empty par-ticles with a diameter of $c a .82$ $\mathrm{nm}$ were identified (Fig. $2 \mathrm{H}$ ), similar to that of authentic virions (Fig. 2I). The fuzzy appearance of these VLPs is indicative of the assembly of the outer capsid consisting of VP2 and VP5 onto the spiky CLP structure formed by VP3 and VP7. However, these VLPs were few in number, often as low as two particles per grid, thus precluding their quantification. Although it could be demonstrated that the major capsid proteins assemble into VLPs, the low yield of VLPs is indicative of partial conversion of CLPs into fully assembled VLPs, possibly as a consequence of the stoichiometry of the expressed proteins.

\subsection{Engineering and assembly of mutant AHSV CLPS}

Although CLPs were synthesized, crystalline formation of AHSV VP7 trimers is thought to impede high-level production. To rationally engineer a mutant version of VP7 that may increase the soluble trimer concentration in the cytoplasm and turnover of CLPs, we generated and assessed protein models. Soluble trimeric VP7 of orbiviruses associate with the surface of the subcore layer and are organized around aqueous channels as hexameric rings, with pentameric rings at the vertices of the icosahedrons (Johnson and Speir, 1997; Grimes et al., 1998). A homology model of a hexameric ring of AHSV-9 VP7 trimers (18 VP7 molecules) in contact with three underlying AHSV-9 VP3 molecules was generated based on a crystallographic reconstruction of BTV-1CLPs (Fig. 3A). A marked structural resemblance exists in the overall architecture of the major core proteins and core particles of these two related orbiviruses (Burroughs et al., 1994; Basak et al., 1996, 1997; Manole et al., 2012), as well as acceptable phylogenetic relationships between their VP3 or VP7 proteins. The amino acid sequence identity shared between VP3 of AHSV-9 and BTV-1 was 57.5\%, while their VP7 proteins shared $42.8 \%$ identity, thus exceeding the 30\% cut-off value for homology modeling (Xiang, 2006). The overall root mean squared distance (RMSD) for the entire heteromultimeric complex was $6.5 \AA$ which, considering the complex size and the number of flexible loops, is good.

Helix 2 (residues 26-43) in the bottom domain of VP7 is solvent exposed, but extremely hydrophobic and shares a high degree of amino acid conservation with BTV (76.5\%) (Fig. 3B). In the AHSV model, VP7 makes 13 different hydrophobic contacts with the VP3 molecules. The $\alpha$-helix 2 regions of three adjoining VP7 monomers largely form the flat base of trimeric VP7 (Fig. 3C). The complete hydrophobic helix 2 and part of the adjoining loops (residues 2050 ) is parallel to, and in close contact with the surface of VP3 (Fig. 3C). Stabilization of helix 2 in relation to the VP3 layer may be mediated by interactions between specific residues in VP7 (Fig. $3 D$ ). The $R_{22}$ residue appears to anchor a loop extending from helix 2 to the main body of VP7 by interacting with the $V_{16}$ backbone, thereby stabilizing the helix. The $\mathrm{S}_{24}$ residue is located in a bend on the loop leading into helix 2 and the side chain may interact with the adjacent residue's $\left(\mathrm{L}_{25}\right)$ backbone, thereby stabilizing the loop and adjoining helix, while the $\mathrm{N}_{38}$ residue appears to interact with $\mathrm{T}_{97}$ located between $\alpha$-helix 4 and 5 in VP7. It is conceivable that the hydrophobicity of the solvent exposed, flat base of trimeric VP7 may be the driving force behind not only their assembly with preformed cores, but also their propensity to self-assembly into crystalline structures. Specific mutations in this region of BTV VP7 were reported to abrogate CLP formation and/or stability (Limn and Roy, 2003).

The smaller top domain of VP7 (residues 121-249) does not interact with VP3 and contains antiparallel $\beta$-sheets and loops. The mutant VP7 utilized in this study to synthesize CLPs contained a 6mer insertion in the RGD motif located on a highly flexible loop in the top domain that is positioned at the interface between two adjacent trimers, making it solvent accessible (Fig. 4A). Insertion mutagenesis of the peptide, KLSRVD, downstream of residue $R_{177}$ resulted in an increase in the predicted hydrophilicity (Fig. 4B) and may reduce interactions within the loop, thereby increasing its flexibility. The mutant protein was more soluble and stable trimer formation was demonstrated (Rutkowska et al., 2011). Comparative analysis of models of native and mutant AHSV-9 VP7 that were generated utilizing a crystallographic reconstruction of the AHSV-4 top domain as homologue, revealed that the 6-mer insertion mutation did not alter the overall predicted structure of the top domain (Fig. 4C). In the native VP7 protein, the RGD-containing loop appears to be stabilized by a polar interaction between the $R_{177}$ and $D_{180}$, while no polar interactions were observed in the mutant RGD-containing loop (Fig. 4C).

The mutant VP7 gene was co-synthesized with VP3 in Sf9 insect cells (Fig. 4D). The size and ultrastructure of purified nanoparticles were indistinguishable from the CLPs comprising VP3 and the wild-type VP7 (Fig. 4E). On average, at least a three-fold increase in the number of mutant CLPs was observed by TEM. The num-ber of similarly prepared CLPs and mutant CLPs within a field at a magnification of 60000 , ranged between 4 and 6 and 13-22 assembled particles, respectively. Fewer VP7 crystalline structures with markedly smaller dimensions and overall dissimilar morphological features were observed in cells infected with 9.3-9.7mut (VP3.VP7mut) (Fig. 4F), compared to those infected with 9.3-9.7 (VP3.VP7) (Fig. 1B). In addition, larger cytoplasmic arrays composed of empty nanoparticles were observed by TEM of sectioned infected cells (Fig. 4F). No similar multimeric structures to those described

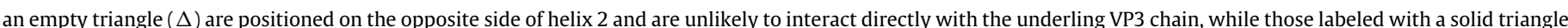

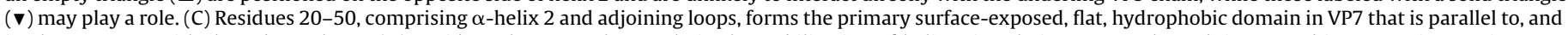

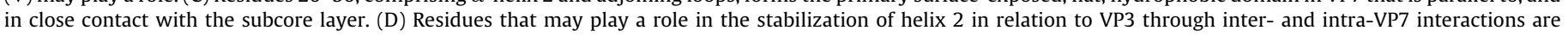
indicated. 
A

Trimer 1

Trimer 2

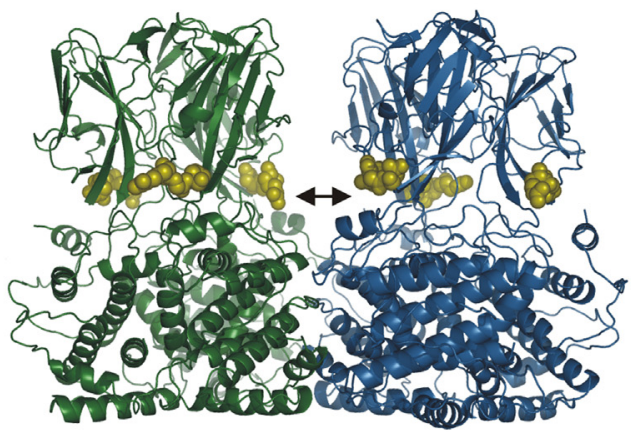

C

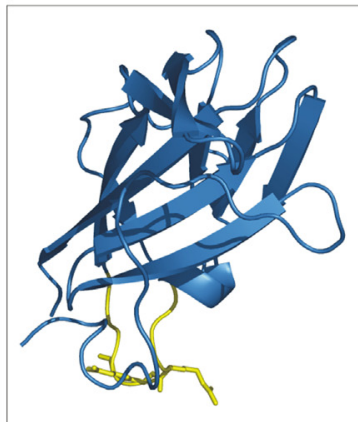

B

Position 170171172173174175176177178179180181182183

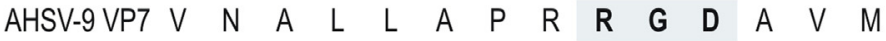
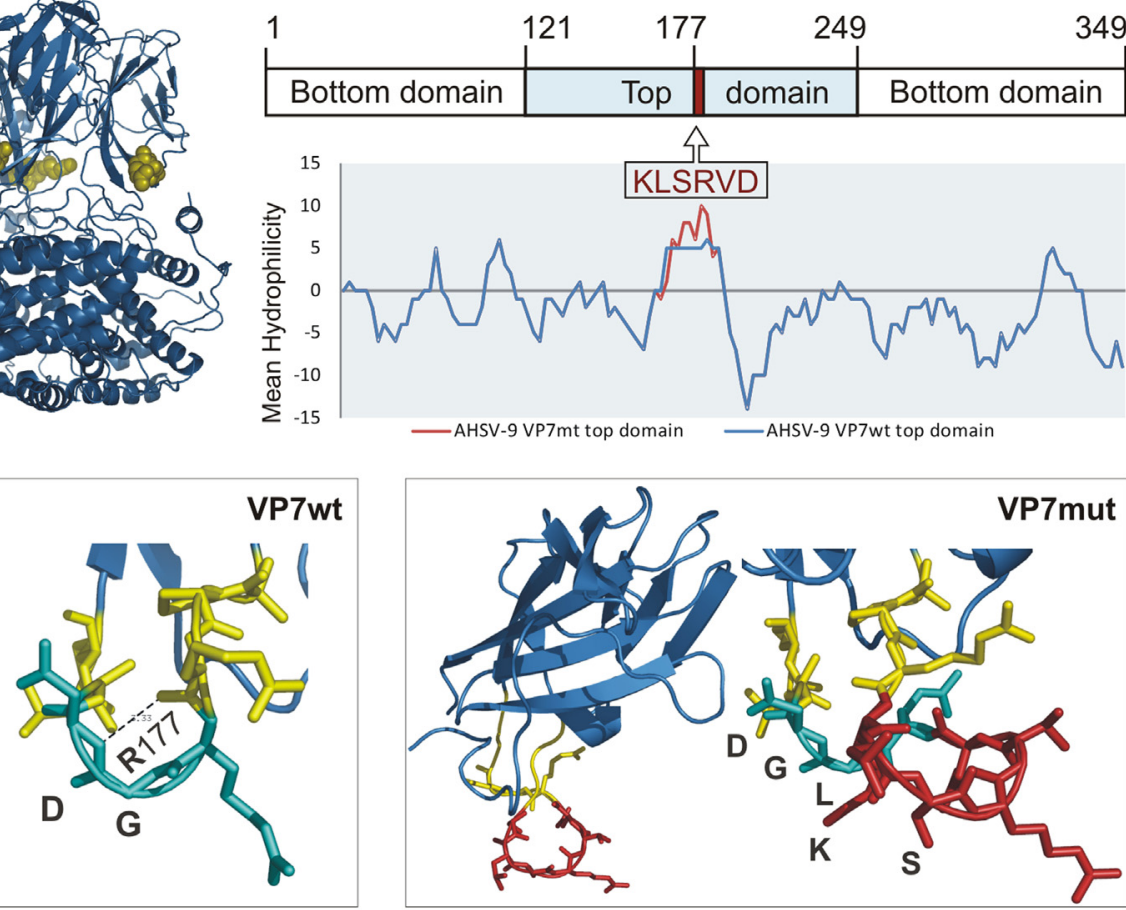

D

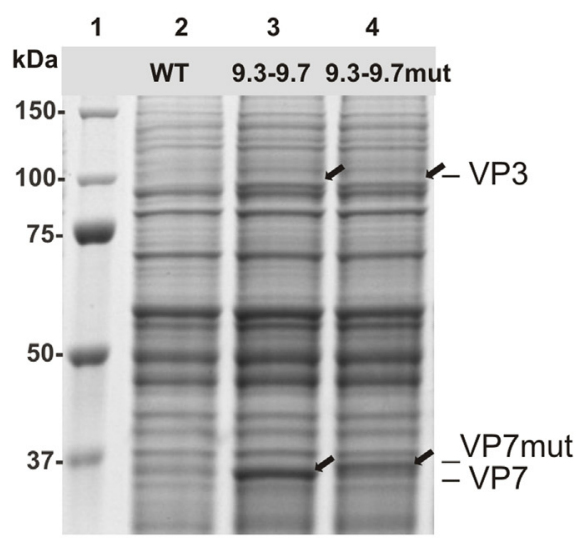

E

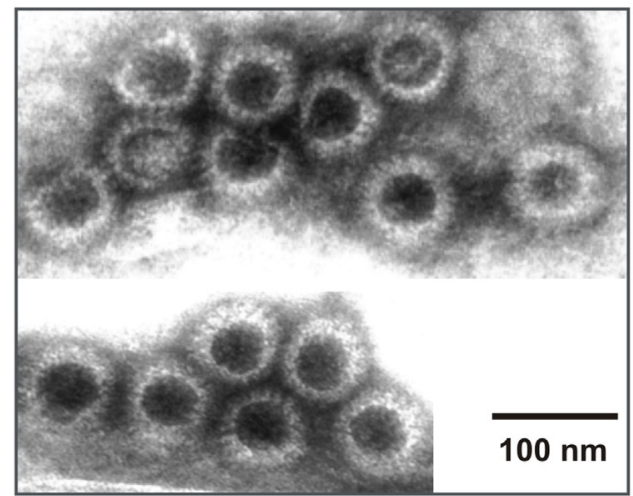

$\mathbf{F}$
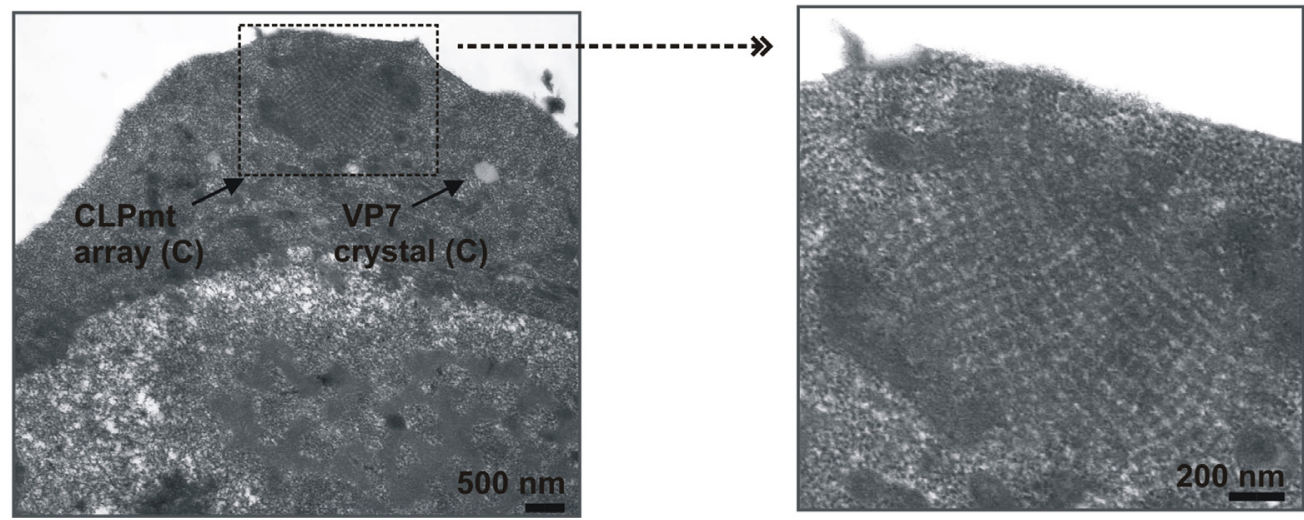

Fig. 4. Mutation of AHSV VP7 and the synthesis of mutant CLPs.

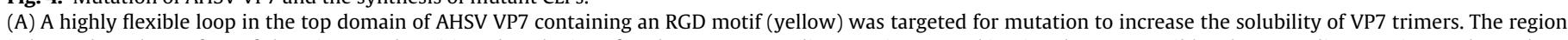

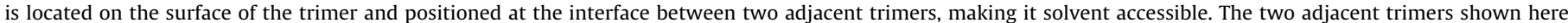

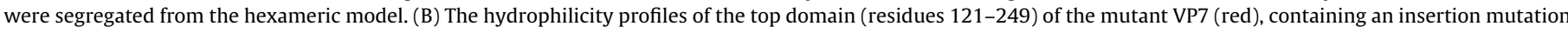

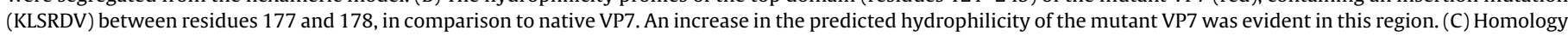

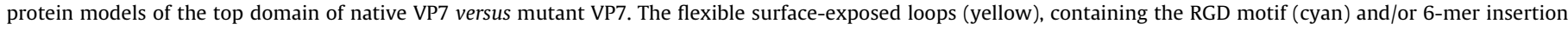


above were observed in mock-infected and wild-type baculovirusinfected cells (Fig. 1D).

\section{Discussion}

In this study, we describe expression of the four major structural proteins of AHSV in different combinations and their assembly into empty virus particles in insect cells. If a VLP-based vaccine for AHS is to be realized, then production of fully assembled CLPs must first be demonstrated, as they act as scaffolds for the assembly of the outer capsid proteins. Although the feasibility of assembling AHSV CLPs in insect cells was previously demonstrated (Maree et al., 1998), the approach relied on co-infection with two recombinant bac-uloviruses expressing either the VP3 or VP7 gene and resulted in mostly partially assembled CLPs.

As a means to improve CLP assembly, a single recombinant baculovirus was constructed to facilitate co-synthesis of AHSV9 VP3 and VP7 in insect cells. Notably, VP7 was synthesized to a much higher level compared to VP3, despite the use of promoters with similar strength. This prominent difference in the relative quantities of VP3 to VP7 was also reported following their individual in vitro and in vivo expression (Maree et al., 1998), as well as in AHSV-infected BHK-21 cells (Grubman and Lewis, 1992). These results and the relative amount in which each protein is required to assemble into particles, presumably thirteen VP7 molecules to two VP3 molecules (Burroughs et al., 1994), suggest the existence of a genetically predetermined, differential quantitative expression mechanism. Linear or paracrystalline cytoplasmic arrays of empty CLPs were visible on electron micrographs in cross-sectioned recombinant VP3 and VP7 baculovirus-infected insect cells, but not in wild-type baculovirus infected cells. This result is indicative of the ability of AHSV CLPs to associate with the cytoskeleton in the absence of the other viral proteins. The prototypical orbivirus virion was also reported to be attached to the cytoskeleton singly or in such arrays (Eaton et al., 1987). The production of CLPs that structurally resembled empty AHSV cores and bound to AHSV VP7 monoclonal antibodies, was demonstrated. The CLPs were characterized by regularity in the spatial distribution of VP7 rings and capsomers, suggesting that fully assembled CLPs were produced.

The in vivo synthesis of partial VLPs, i.e. CLPs associated with either VP2 or VP5, was demonstrated. This result is in agreement with in vitro BTV capsid assembly studies reported by Liu et al. (1992). These results indicate that the two different capsid proteins can independently interact with preformed CLPs. Therefore, it may be possible to produce immunogenic partial AHS VLPs composed of the major core proteins of one serotype and VP2s of each of the nine serotypes. It is also feasible that the number of partial VLPs required to afford complete protection in vaccinated animals could be reduced by artificially combining the VP2s of more than one serotype in one particle. The presence of both proteins may, however, stabilize each other in the outer capsid layer. Liu et al. (1992) demonstrated that the level of interaction of BTV VP2 with CLPs is significantly reduced when expressed in the absence of VP5. It is thought that the interaction of VP5 with VP2 may enhance the conformation of VP2 (Cowley and Gorman, 1989; Mertens et al., 1989; DeMaula et al., 2000). Weak interactions of trimeric VP5 with both trimeric VP2 and VP7 have been identified and is likely to permit unfurling of the surface of VP5 trimer during virus entry, as well as shedding of the outer capsid layer to release the thetranscriptionally-active core particle (Zhang et al., 2010).
Although complete AHSV VLPs were synthesized in this study, their yield was low.

The production of fully assembled CLPs represents a signifi-cant improvement over the previously used co-infection approach. However, the overall yield appeared to be low as evidenced by the sparse distribution of individual particles on electron micrographs. Aggregated material was also observed, but it could not be concluded with certainty that it contained paracrystalline CLPs. Both cytoplasmic and nuclear crystalline VP7, with small to extremely large dimensions, were observed in infected insect cells. This characteristic of AHSV VP7 to self-assemble (Burroughs et al., 1994; Chuma et al., 1992; Maree and Paweska, 2005) reduces the number of soluble trimers that can interact with the pre-formed VP3 subcore-like particles. In this regard, it is worth noting that BTV VP7 trimers are soluble and do not aggregate into crystalline structures. High yields of BTV CLPs produced in the baculovirus expression system are typically reported (French and Roy, 1990; Hewat et al., 1992; Belyaev and Roy, 1993; Roy et al., 1997).

To rationally engineer AHSV VP7 trimers with increased solubility and without abrogating their self-assembly with VP3 into CLPs, we generated and analyzed protein homology models of a hexameric ring of VP7 trimers in interaction with the subcore layer. Although deductions from this heteromultimeric model at residue level were limited due to the resolution of the crystallographic template (3.50 $\AA$ ), the major region of VP7 that interacts with VP3 could be identified with confidence. This primary interaction is hydrophobic in nature and engages the flat base of the trimers that is parallel to the subcore layer. This interfacial region comprises of $\alpha$-helix 2 and part of the adjoining loops, and is rich in hydrophobic amino acids. The helix is predominantly conserved between AHSV and BTV. Limn and Roy (2003) reported that substitution of residues in this region of BTV-10 VP7, that are similar or identical to the corresponding residues of AHSV-9 VP7, with dissimilar amino acids, did not abrogate trimer forma-tion, but reduced CLP stability and/or formation The corresponding residues in AHSV-9 VP7 $\left(\mathrm{R}_{22}, \mathrm{~S}_{24}, \mathrm{M}_{30}, \mathrm{~L}_{33}, \mathrm{G}_{34}, \mathrm{~A}_{36}, \mathrm{~N}_{38}, \mathrm{~N}_{45}\right.$ and $\mathrm{S}_{47}$ ) were assessed in the model and putative inter- or intra-VP7 interactions could be identified that are thought to play a key role in the stabilization of $\alpha$-helix 2 in relation to the VP3 layer. Although the hydrophobicity of the flat base in the bottom domain of trimeric VP7 may contribute to their aggregation, it is evident that its composition is essential to not only mediate hydropho-bic interfacial VP3 and VP7 interaction, but also to stabilize VP7 helix 2.

Consequently, we aimed to increase the solubility of VP7 by increasing the hydrophilicity of the top domain. We identified a highly flexible surface-exposed loop located in the lower part of the top domain at the interface between two adjacent trimers for mutagenesis. Due to these attributes, as well as the absence of predicted interactions between residues in this flexible loop and other residues in the same or adjacent trimers, an insertion mutation in this region was not predicted to induce significant structural changes. A 6-mer peptide was inserted in front of the RGD motif in this region as described by Rutkowska et al. (2011). A comparison of the homology models that were generated utilizing a crystallographic reconstruction of the top domain of AHSV-4 as homologue, did not reveal structural dissimilarities in the $\beta$-sheets and remain-ing loops. An increase in the predicted hydrophilicity was also observed in the mutant version of VP7, due to the composition of the 
peptide and an increase in the flexibility of this surface-exposed loop. Following co-synthesis of the mutant VP7 with VP3 in insect cells, we demonstrated that the efficiency of CLP production can be improved by utilizing this strategy. An increase in the yield of the resultant mutant CLPs was observed by TEM, while a decrease in the number, size and morphology of crystalline VP7 was evident. These results provided the first evidence that the turnover of AHSV CLPs production can be increased with a rational protein engineering approach aimed to increase the number of cytosolic trimeric VP7 molecules that remains in solution.

\section{Conclusion}

To date, the production of heteromultimeric AHSV CLPs and VLPs has remained an elusive goal. Here, we have demonstrated the synthesis of multilayered, empty AHSV particles. The results obtained in this study, however, also suggested that the goal of developing AHS VLP-based vaccines may not be achieved readily. This, therefore, necessitates that the expression system be optimized. For this purpose, genetic manipulation approaches aimed at increasing the yield of soluble VP7, without abrogating particle formation or disrupting major serogroup-specific epitopes, could further be investigated, as well as expression of a codon-optimized VP3 gene to increase the yield of VP3. In addition, quadruple baculovirus expression vectors that enable simultaneous expression of all four of the major capsid proteins of AHSV may be investigated as a means to facilitate production of VLPs. The synthesis of these complex multilayered, heteromultimeric particles is challenging. Nevertheless, the successes achieved with BTV VLP-based vaccines as a means to protect animals from disease (Martı́nezTorrecuadrada et al., 1994; Noad and Roy, 2003; Roy et al., 2009; Stewart et al., 2013) warranted an investigation to determine whether AHSV CLPs and VLPs could be produced in insect cells with the baculovirus expression system.

The practical utility of AHSV VLPs as vaccines may, however, be limited in terms of cost-effectiveness, technical complexity of production, as well as problems with reproducibility and upscaling of production. It can be anticipated that these difficulties may intensify during large-scale production of multiple VLPs. The requirement for a polyvalent vaccine that includes multiple AHSV VLPs covering the VP2s of all nine serotypes to induce complete protection may further limit its practical use. However, VLPs may be of practical use if a monovalent vaccine is required for the control of an epizootic involving a single serotype. The ease of delivery will remain similar to the current conventional vaccine, depending on the coverage of the different serotypes in a specific vaccine formulation and stability of the synthetic particles.

\section{Acknowledgements}

This research was funded through financial support received from the Agricultural Research Council (ARC) and National Research Foundation (NRF). The authors thank the University of Pretoria, South Africa (Departments of Genetics and Microbiology) for providing cloned cDNA copies of AHSV-9 segments 2 and 6, as well as recombinant baculovirus 9.2 (VP2). VP7 monoclonal antibody was kindly provided by Mr. W. van Wyngaardt (ARC-OVI, South Africa). We give credit for the electron micrographs of the authentic AHSV cores and virions (Figure 1G, 2I) to Dr. J.J.O. Koekemoer and Mr. H.J. Els (VRI, 1968), respectively. We acknowledge Dr. A.A. van Dijk for her support in the past towards synthe-sizing completely-assembled AHSV CLPs. We also thank Dr. J.J.O. Koekemoer and Dr. B. Mans from the ARC-OVI for reviewing this manuscript.

\section{References}

Alexander, R.A., 1948. The 1944 epizootic of horse sickness in the Middle East. Onderstepoort J. Vet. Sci. Anim. Indus. 2, 375-391.

Basak, A.K., Gouet, P., Grimes, J., Roy, P., Stuart, D., 1996. Crystal structure of the top domain of African horse sickness virus VP7, comparisons with bluetongue virus VP7. J. Virol. 70, 3797-3806.

Basak, A.K., Grimes, J.M., Gouet, P., Roy, P., Stuart, D.I., 1997. Structures of orbivirus VP7, implications for the role of this protein in the viral life cycle. Structure 5 $871-883$.

Belyaev, A.S., Roy, P., 1993. Development of baculovirus triple and quadruple expression vectors: co-expression of three or four bluetongue virus proteins and the synthesis of bluetongue virus-like particles in insect cells. Nucleic Acids Res. 21, 1219-1223.

Bremer, C.W., 1976. A gel electrophoretic study of the protein and nucleic acid components of African horse sickness virus. Onderstepoort J. Vet. Res. 43, 193-199.

Burroughs, J.N., O’Hara, R.S., Smale, C.J., Hamblin, C., Walton, A., Armstrong, R., Mertens, P.P.C., 1994. Purification and properties of virus particles, infectious subviral particles, cores and VP7 crystals of African horse sickness virus serotype 9. J. Gen. Virol. 75, 1849-1857.

Carpano, M., 1931. African horse sickness observed particularly in Egypt and in Eritrea. Min. Agric. Tech. Sci. Serv. Bull. Cairo 115, 1-41.

Carrillo-Tripp, M., Shepherd, C.M., Borelli, I.A., Venkataraman, S., Lander, G., Natarajan, P., Johnson, J.E., Brooks 3rd, C.L., Reddy, V.S., 2008. VIPERdb2: an enhanced and web API enabled relational database for structural virology. Nucleic Acids Res. 37 (Database issue), D436-D442.

Chiam, R., Sharp, E., Maan, S., Rao, S., Mertens, P., Blacklaws, B., Davis-Poynter, N., Wood, J., Castillo-Olivares, J., 2009. Induction of antibody responses to African horse sickness virus (AHSV) in ponies after vaccination with recombinant modified vaccinia Ankara (MVA). PLoS One 4, 1-9.

Chuma, T., Le Blois, H., Sanchez-Vizcaino, J.M., Diaz-Laviada, M., Roy, P., 1992. Expression of the major core antigen VP7 of African horse sickness virus by a recombinant baculovirus and its use as a group-specific diagnostic reagent. J. Gen. Virol. 73, 925-931.

Coetzer, J.A.W., Guthrie, A., 2004. African horse sickness. In: Coetzer, J.A.W., Tustin, R.C. (Eds.), Infectious Diseases of Livestock. , Second edition. Oxford University Press, South Africa, pp. 1231-1246.

Cowley, J.A., Gorman, B.M., 1989. Cross-neutralisation of genetic reassortants: conformation VP2 epitopes of bluetongue virus serotypes 20 and 21. Vet. Microbiol. 19, 37-51.

DeLano, W.L., 2002. The PyMOL Molecular Graphics System. DeLano Scientific, San Carlos, CA.

DeMaula, C.D., Bonneau, K.R., MacLachlan, N.J., 2000. Changes in the outer capsid proteins of bluetongue virus serotype ten that abrogate neutralisation by monoclonal antibodies. Virus Res. 67, 59-66.

Du Plessis, M., Nel, L.H., 1997. Comparative sequence analysis and expression of the M6 gene, encoding the outer capsid protein VP5, of African horse sickness virus serotype nine. Virus Res. 47, 41-49.

Eaton, B.T., Hyatt, A.D., White, J.R., 1987. Association of bluetongue virus with the cytoskeleton. Virology 157, 107-116.

Fiser, A., Sali, A., 2003. Modeller: generation and refinement of homology-based protein structure models. Methods Enzymol. 374, 461-491.

French, T.J., Roy, P., 1990. Synthesis of bluetongue virus (BTV) core-like particles by a recombinant baculovirus expressing the two major structural core proteins of BTV. J. Virol. 64, 1530-1536.

Grgacic, E.V.L., Anderson, A., 2006. Virus-like particles, passport to immune recognition. Methods 40, 60-65.

Grimes, J.M., Burroughs, J.N., Gouet, P., Diprose, J.M., Malby, R., Zientara, S., Mertens, P.P., Stuart, D.I., 1998. The atomic structure of the bluetongue virus core. Nature 395, 470-478.

Grubman, M.J., Lewis, S.A., 1992. Identification and characterization of the structural and nonstructural proteins of African horse sickness virus and determination of the genome coding assignments. Virology 186, 444-451.

Guthrie, A.J., Quana, M., Lourensa, C.W., Audonnet, J., Minkeb, J.M., Yao, J., He, L. Nordgren, R., Gardner, I.A., MacLachlan, N.J., 2009. Protective immunisation of horses with a recombinant canarypox virus vectored vaccine co-expressing genes encoding the outer capsid proteins of African horse sickness virus. Vaccine $16,4434-4438$

Hewat, E.A., Booth, T.F., Loudon, P.T., Roy, P., 1992. Three-dimensional reconstruction of baculovirus expressed bluetongue virus core-like particles by cryo-electron microscopy. Virology 189, 10-20.

Howell, P.G., 1962. The isolation and identification of further antigenic types of African horse sickness virus. Onderstepoort J. Vet. Res. 29, 139-149.

Howell, P.G., 1963. African horse sickness, vol. 2. FAO Agricultural Studies, pp. 71-108.

Johnson, J.E., Speir, J.A., 1997. Quasi-equivalent viruses: a paradigm for protein assemblies. J. Mol. Biol. 269, 665-675. 
Kang, S.M., Yoo, D.G., Lipatov, A.S., Song, J.M., Davis, C.T., Quan, F.S., Chen, L.M., Donis, R.O., Compans, R.W., 2009. Induction of long-term protective immune responses by influenza H5N1 virus-like particles. PLoS One 4, 4667-4677. Lambert, C., Leonard, N., De Bolle, X., Depiereux, E., 2002. ESyPred3D: prediction of proteins 3D structures. Bioinformatics 18, 1250-1256.

Limn, C.H., Roy, P., 2003. Intermolecular interactions in a two-layered viral capsid that requires a complex symmetry mismatch. J. Virol. 77, 11114-11124.

Liu, H.M., Booth, T.F., Roy, P.J., 1992. Interactions between bluetongue virus core and capsid proteins translated in vitro. J. Gen. Virol. 73, 2577-2584. Lubroth,

J., 1988. African horse sickness and the epizootics in Spain 1987. Equine Prac. 10, 26-33.

Maclachlan, N.J., Guthrie, A.J., 2010. Re-emergence of bluetongue, African horse sickness, and other orbivirus diseases. Vet. Res. 41, 35.

Manole, V., Laurinmäki, P., Van Wyngaardt, W., Potgieter, C.A., Wright, I.M., Venter, G.J., van Dijk, A.A., Sewell, B.T., Butcher, S.J., 2012. Structural insight into African horse sickness virus infection. J. Virol. 86, 7858-7866.

Maree, S., Durbach, S., Huismans, H., 1998. Intracellular production of African horse sickness virus core-like particles by expression of the two major core proteins, VP3 and VP7, in insect cells. J. Gen. Virol. 79, 333-337.

Maree, S., Paweska, J.T., 2005. Preparation of African horse sickness virus VP7 antigen via a simple method and validation of a VP7-based indirect ELISA for the detection of group-specific IgG antibodies in horse sera. J. Virol. Methods 125, 55-65.

Martı́nez-Torrecuadrada, J.L., Diaz-Laviada, M., Roy, P., Sanchez, C., Vela, C., Sánchez-Vizcaíno, J.M., Casal, J.I., 1996. Full protection against African horse sickness (AHS) in horses induced by baculovirus-derived AHS virus serotype 4 VP2, VP5 and VP7. J. Gen. Virol. 77, 1211-1221.

Martı́nez-Torrecuadrada, J.L., Iwata, H., Venteo, A., Casal, I., Roy, P., 1994. Expression and characterization of the two outer capsid proteins of African horse sickness virus, the role of VP2 in virus neutralization. Virology 202, 348-359.

Mellor, P.S., Hamblin, C., 2004. African horse sickness. Vet. Res. 35, 445-466.

Mertens, P.P.C., Pedley, S., Cowley, J., Burroughs, J.N., Corteyn, A.H., Jeggo, M.H., Jennings, D.M., Gorman, B.M., 1989. Analysis of the roles of bluetongue virus outer capsid proteins VP2 and VP5 in determination of virus serotype. Virology $170,561-565$

Noad, R., Roy, P., 2003. Virus-like particles as immunogens. Trends Microbiol. 11, 438-444.

O’Reilly, D.R., Miller, L.K., Luckow, V.A., 1994. Baculovirus Expression Vectors. A Laboratory Manual. Oxford University Press, New York.

Oellermann, R.A., Els, H.J., Erasmus, B.J., 1970. Characterization of African horse sickness virus. Arch. Gesamte Virusforsch. 29, 163-174.

Romito, M., du Plessis, D.H., Viljoen, G.J., 1999. Immune repsonse in a horse inoculated with the VP2 gene of African horse sickness virus. Onderstepoort J Vet. Res. 66, 139-144.

Roy, P., Bishop, D.H., Howard, S., Aitchison, H., Erasmus, B., 1996. Recombinant baculovirus-synthesized African horse sickness virus (AHSV) outer-capsid protein VP2 provides protection against virulent AHSV challenge. J. Gen. Virol. 77, 2053-2057.
Roy, P., Bishop, D.H., LeBlois, H., Erasmus, B.J., 1994. Long-lasting protection of sheep against bluetongue challenge after vaccination with virus-like particles, evidence for homologous and partial heterologous protection. Vaccine 12, 805-811.

Roy, P., Boyce, M., Noad, R., 2009. Prospects for improved bluetongue vaccines. Nat. Rev. 7, 120-128.

Roy, P., French, T., Erasmus, B.J., 1992. Protective efficacy of virus-like particles for bluetongue disease. Vaccine 10, 28-32.

Roy, P., Mikhailov, M., Bishop, D.H., 1997. Baculovirus multigene expression vectors and their use for understanding the assembly process of architecturally complex virus particles. Gene 190, 119-129.

Rutkowska, D.A., Meyer, Q.C., Maree, F.F., Vosloo, W., Fick, W., Huismans, H., 2011. The use of soluble African horse sickness viral protein 7 as antigen delivery and presentation system. Virus Res. 156, 35-48.

Sambrook, J., Russell, D.W., 2001. Molecular Cloning: A Laboratory Manual, 3rd edition. Cold Spring Harbor Laboratory Press, New York.

Scanlen, M., Paweska, J.T., Verschoor, J.A., van Dijk, A.A., 2002. The protective efficacy of a recombinant VP2-based African horse sickness vaccine candidate is determined by adjuvant. Vaccine 20, 1079-1088.

Stewart, M., Bhatia, Y., Athmarana, T.N., Noad, R., Gastaldi, C., Dubois, E., Russo, P., Thiéry, R., Sailleau, C., Bréard, E., Zientara, S., Roy, P., 2010. Validation of a novel approach for the rapid production of immunogenic virus-like particles for bluetongue virus. Vaccine 28, 3047-3054.

Stewart, M., Dubois, E., Sailleau, C., Bréard, E., Viarouge, C., Desprat, A., Thiéry, R., Zientara, S., Roy, P., 2013. Bluetongue virus serotype 8 virus-like particles protect sheep against virulent virus infection as a single or multi-serotype cocktail immunogen. Vaccine 31, 553-558.

Van Dijk, A.A., 1998. African horse sickness vaccine development. In: Wade, J.F. (Ed.), Proceedings of the Eighth International Conference of Equine Infectious Diseases, 261-265.

Van Wyngaardt, W., Du Plessis, D.H., van Wyngaardt, S., Verschoor, J.A., 1992. Production and properties of monoclonal antibodies against African horse sickness virus, serotype 3. Onderstepoort J. Vet. Res. 59, 129-133.

Venter, M., Napier, G., Huismans, H., 2000. Cloning, sequencing and expression of the gene that encodes the major neutralisation-specific antigen of African horse sickness virus serotype 9. J. Virol. Methods 86, 41-53.

von Teichman, B.F., Dungu, B., Smit, T.K., 2010. In vivo cross-protection to African horse sickness serotypes 5 and 9 after vaccination with serotypes 8 and 6 . Vaccine 28, 6505-6517.

Xiang, Z., 2006. Advances in homology protein structure modelling. Curr. Protein Pept. Sci. 7, 217-227.

Zhang, X., Boyce, M., Bhattacharya, B., Zhang, X., Schein, S., Roy, P., Zhou, Z.H., 2010 Bluetongue virus coat protein VP2 contains sialic acid-binding domains, and VP5 resembles enveloped virus fusion proteins. PNAS 107, 6292-6297.

Zwart, L., Potgieter, C.A., Clift, S.J., van Staden, V., 2015. Characterising non-structural protein NS4 of African horse sickness virus. PLoS One 10 (4), e0124281. 


\section{Supplementary data}

Supplementary Fig. S1.

Immunoblot analyses of lysates prepared from Sf9 cells infected with recombinant baculoviruses expressing the major capsid proteins of AHSV. (A) Schematic representation of the three concentric protein layers of AHSV composed of four different major capsid proteins (VP2, VP3, VP5 and VP7). The multimeric state and sizes of protein monomers are shown below the particle. (B-E) Colorimetric immunoblots confirming VP3, VP2, VP5 and VP7 expression, respectively. Sf9 cells were infected with single-gene recombinant baculoviruses containing the coding regions of each of the four major capsid proteins and the cell lysates were resolved by SDS-PAGE analyses. The separated proteins were blotted onto nitrocellulose membranes and subjected to immunoblot analyses with primary antibodies against the protein of interest. The lanes contains lysates from cells infected wild-type (WT) or recombinant baculoviruses expressing the capsid proteins as follows: (B) Standard protein size marker (lane 1); VP3 (lane 2) WT (lane 3). (C) VP7 (lane 1); Mockinfected cells (lane 2); WT (lane 3). (D) Standard protein size marker (lane 1); Mockinfected cells (lane 2); WT (lane 3); VP2 (lane 4). (E) Standard protein size marker (lane 1); WT (lane 2); VP5 (lane 3). The sizes of the standard molecular weight markers are indicated to the left of each figure.

A
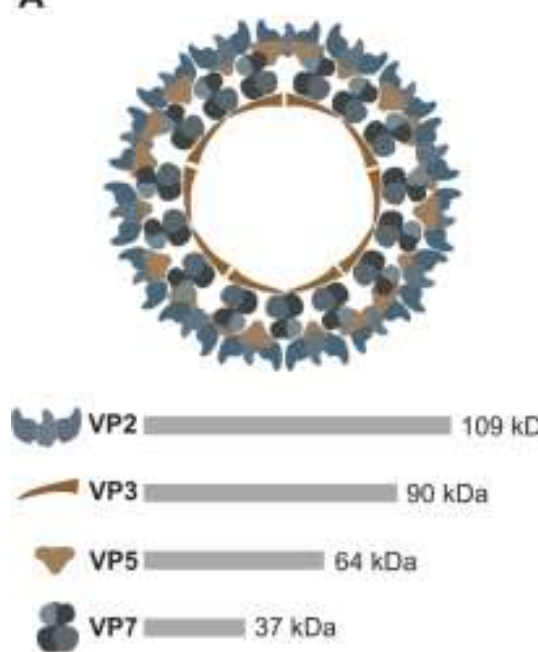

B

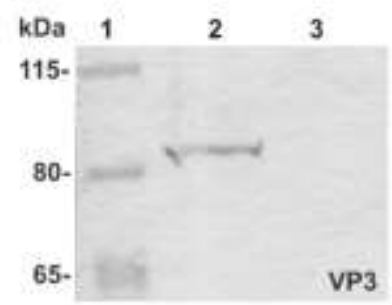

D

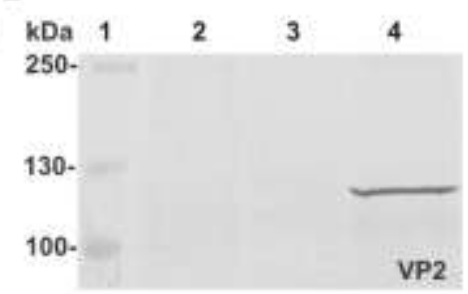

C

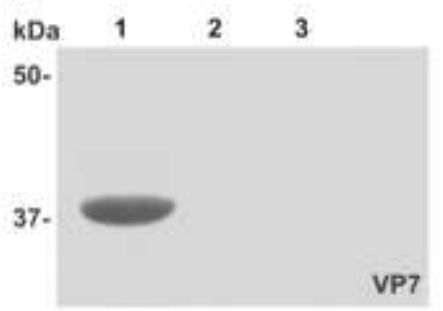

E

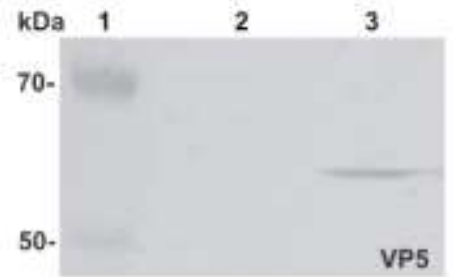


Supplementary Fig. S2.

Antibody decoration of semi-purified AHSV CLPs. (A) Transmission electron micrographs of nanosized particles $(72 \mathrm{~nm})$ that were purified from insect cells cosynthesizing AHSV VP3 and VP7 and negatively contrasted with uranyl acetate. The size and overall ultrastructure of the particles resembled empty AHSV cores. (B) Transmission electron micrographs of CLPs bound to AHSV VP7-specific monoclonal antibodies. The overall ultrastructure of the decorated particles were consistent with that of empty AHSV cores. The antibody did not bind to other heteromultimeric particles in the protein sample, such as baculoviruses.

A

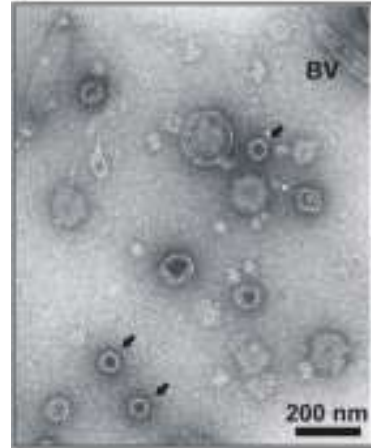

B

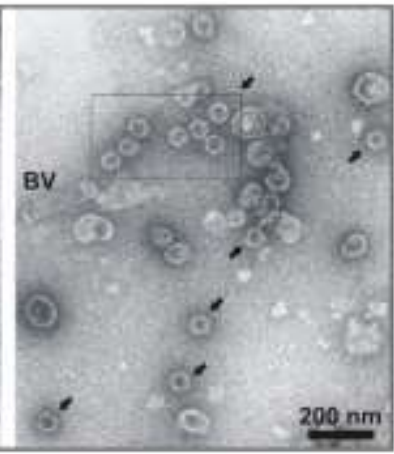

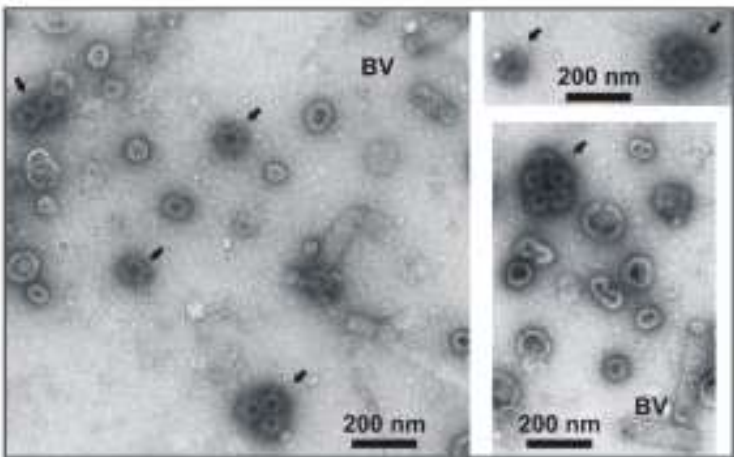

